\title{
Treatment Costs and Factors Associated with Glycemic Control among Patients with Diabetes in the United Arab Emirates
}

\author{
Seung-Mi Lee', Inmyung Song' ${ }^{1}$ David Suh ${ }^{2}$, Chongwon Chang ${ }^{1}$, Dong-Churl Suh ${ }^{1, *}$ \\ 'College of Pharmacy, Chung-Ang University, Seoul, Korea; ${ }^{2}$ School of Public Health, Columbia University, New York, NY, USA
}

Background: We aimed to estimate the proportion of patients with diabetes who achieved target glycemic control, to estimate diabetes-related costs attributable to poor control, and to identify factors associated with them in the United Arab Emirates.

Methods: This retrospective cohort study used administrative claims data handled by Abu Dhabi Health Authority (January 2010 to June 2012) to determine glycemic control and diabetes-related treatment costs. A total of 4,058 patients were matched using propensity scores to eliminate selection bias between patients with glycosylated hemoglobin ( $\mathrm{HbA1c}$ ) $<7 \%$ and $\mathrm{HbA} 1 \mathrm{c} \geq 7 \%$. Diabetes-related costs attributable to poor control were estimated using a recycled prediction method. Factors associated with glycemic control were investigated using logistic regression and factors associated with these costs were identified using a generalized linear model.

Results: During the 1-year follow-up period, $46.6 \%$ of the patients achieved $\mathrm{HbA1c}<7 \%$. Older age, female sex, better insurance coverage, non-use of insulin in the index diagnosis month, and non-use of antidiabetic medications during the follow-up period were significantly associated with improved glycemic control. The mean diabetes-related annual costs were $\$ 2,282$ and $\$ 2,667$ for patients with and without glycemic control, respectively, and the cost attributable to poor glycemic control was $\$ 172$ (95\% confidence interval [CI], \$164-180). The diabetes-related costs were lower with mean $\mathrm{HbA1c}$ levels $<7 \%$ (cost ratio, $0.94 ; 95 \% \mathrm{Cl}, 0.88-0.99$ ). The costs were significantly higher in patients aged $\geq 65$ years than those aged $\leq 44$ years (cost ratio, $1.45 ; 95 \% \mathrm{Cl}$, 1.25-1.70).

Conclusion: More than $50 \%$ of patients with diabetes had poorly controlled $\mathrm{HbA1c}$. Poor glycemic control may increase diabetes-related costs.

Key words: Diabetes mellitus, Blood glucose, Glycosylated hemoglobin A, Health care costs, Administrative claims

\author{
Received July 30, 2018 \\ Reviewed August 31, 2018 \\ Accepted October 25, 2018 \\ ${ }^{*}$ Corresponding author \\ Dong-Churl Suh \\ https://orcid.org/0000-0002-2304-8037 \\ College of Pharmacy, Chung-Ang \\ University, 84 Heukseok-ro, Dongjak-gu, \\ Seoul 06974, Korea \\ Tel: +82-2-820-5600 \\ Fax: +82-2-813-0650 \\ E-mail:dongsuh75@gmail.com
}

The first two authors contributed equally to this study.

\section{INTRODUCTION}

Diabetes mellitus is a major chronic disease affecting an estimated 382 million people globally in $2013^{1}$, with an estimated prevalence of $20 \%$ in the United Arab Emirates (UAE). ${ }^{2,3}$ Therefore, it is becoming a major public health concern.

Raised glucose level or diagnosed diabetes is a critical factor in metabolic syndrome. ${ }^{4}$ Improved glycemic control in diabetes is associated with a lower risk of diabetic complications and reduced all-cause and cardiovascular mortality. ${ }^{5,6}$ Glycemic control is typically assessed using glycosylated hemoglobin (HbAlc) levels, which reflect the average blood glucose levels over the previous 2-3-month period. ${ }^{7-9}$ Each $1 \%$ reduction in $\mathrm{HbAlc}$ in patients with type 2 diabetes mellitus (T2DM) decreases the risk for diabetes-related mor-

Copyright $\odot 2018$ Korean Society for the Study of Obesity

(a) This is an Open Access article distributed under the terms of the Creative Commons Attribution Non-Commercial License (http://creativecommons.org/licenses/by-nc/4.0/) which permits unrestricted non-commercial use, distribution, and reproduction in any medium, provided the original work is properly cited. 
tality by $21 \%$ and microvascular complications by $37 \% .{ }^{10}$ Because of the importance of glycemic control in patients with diabetes, the American Diabetes Association and UAE diabetes management guidelines recommend a specific $\mathrm{HbAlc}$ target of $<7 \%$ for adults with diabetes. ${ }^{3,11}$ However, the proportion of patients with good glycemic control remains low, despite the importance of glycemic control. In the United States, the proportion of adults with HbAlc $<7 \%$ was only $53 \%$ of patients with diabetes in 2007-2010, despite an increase over time ${ }^{12}$, and only $33.3 \%$ of adults with diagnosed diabetes in the UAE achieve the glycemic goal. ${ }^{13}$

Diabetes also presents a huge economic burden, with a total estimated cost of $\$ 245$ billion in 2012 in the U.S. and treatment costs that are estimated at 2.3 times that of people without the disease. ${ }^{14}$ In $\mathrm{Al}$ Ain, UAE, the total annual direct medical costs of diabetes among patients without complications were estimated to be 3.2 times higher than the per capita health care expenditure, and the costs increased even further with the presence of complications. ${ }^{15}$ Furthermore, elevated $\mathrm{HbA1c}$ levels are associated with substantial medical costs, which increase even further with increases in $\mathrm{HbAlc}$ levels. ${ }^{16}$ There is considerable evidence that improved glycemic control results in medical cost savings ${ }^{17}$; a sustained reduction in $\mathrm{HbAlc}$ in adults with diabetes is associated with significant cost savings within the first 1-2 years of improvement. ${ }^{18}$

Although a number of studies have examined the relationship between patient characteristics, glycemic control, and the diabetesrelated treatment $\operatorname{costs}^{7-9,19-21}$, little is known about factors influencing glucose control and diabetes-related costs in patients with diabetes in the UAE. Therefore, the objectives of this study were to estimate the proportion of patients with diabetes who achieve the glycemic target, to identify factors associated with poor glycemic control, to estimate diabetes-related costs attributable to glycemic control, and to identify the characteristics associated with diabetesrelated costs in patients newly diagnosed diabetes in the UAE.

\section{METHODS}

\section{Data source and study population}

This study is a retrospective cohort analysis using the knowledge engine of health administrative claims database handled by $\mathrm{Abu}$ Dhabi Health Authority. The Abu Dhabi Health Authority is the regulatory body of the Emirate's healthcare system established to monitor the health status of its residents and ensure the quality of healthcare for its community. Knowledge engine of health administrative claims database is a platform built to collect health-related information and encounter claims data of the residents that can be analyzed for health status monitoring, regulation, and policy-making purposes. The data set consists of administrative information, diagnoses, activity, and observation elements. Administrative information describes the patients and claims, including financial data and encounters. Activity data include consultations and diagnostic and treatment activities, whereas observation data include specific observations as a result of medical activities (e.g., a lab test). ${ }^{22}$

Data comprised all administrative health claims from January 2010 to June 2012. Eligible patients with diabetes were defined as patients (1) who met specified inclusion criteria for new diabetes diagnosis including type 1 , type 2 , and unspecified type during the enrollment period from July 2010 to June 2011; (2) who were not diagnosed with diabetes during the 6 months prior to the index month; (3) who can be followed up for at least 1 year from the index month; and (4) who had at least two HbAlc values, including the baseline $\mathrm{HbAlc}$ level during the follow-up period. The index month was defined as the first month of diagnosis for diabetes during the enrollment period, and the identified patients with diabetes were followed for 1 year from the index month.

The diagnosis of diabetes was confirmed by at least one of the following criteria: (1) diagnosis of diabetes based on the International Classification of Diseases, Ninth Revision, Clinical Modification (ICD-9-CM) code of 250.xx, (2) at least one pharmacy claim for antidiabetic medications that was classified under the anatomical therapeutic chemical class code of A10, (3) HbAlc level $\geq 6.5 \%$, (4) fasting plasma glucose level $\geq 126 \mathrm{mg} / \mathrm{dL}$ (7.0 mmol/L), or (5) 2-hour plasma glucose level $\geq 200 \mathrm{mg} / \mathrm{dL}(11.1 \mathrm{mmol} / \mathrm{L})$ in a 75 g oral glucose tolerance test.

Patients were excluded if they were diagnosed with human immunodeficiency virus infection (ICD-9-CM codes 042, 043, V08), organ or tissue transplants (ICD-9-CM codes 996.8, V42, V43, V49.83, V58.44, E878.0), malignancy (ICD-9-CM codes 140239), pregnancy (ICD-9-CM codes 633-650, V22, V23), conditions originating in the perinatal period (ICD-9-CM codes 760779), or alteration of consciousness including coma, transient alter- 
ation of awareness, and persistent vegetative state (ICD-9-CM code 780.0) because these conditions could affect the study outcomes (i.e., screening rate, diagnosis rate, total treatment costs, or diabetes-related costs).

\section{Study variables}

The primary study outcome variable was glycemic control and the secondary outcome variable was annual diabetes-related costs. Glycemic control was defined as achievement of a follow-up $\mathrm{HbAlc}<7 \% .{ }^{11}$ Baseline $\mathrm{HbAlc}$ level was measured during the index month, and the follow-up HbAlc level was defined as the average of the $\mathrm{HbAlc}$ values measured during the follow-up period. This study examined the impact of glycemic control on diabetesrelated costs. Diabetes-related costs were calculated by adding medical and prescription costs for the treatment of diabetes and diabetes-related comorbidities, such as nephropathy, neuropathy, retinopathy/macular edema, cardiovascular disease, cerebrovascular disease, and skin disease, during the follow-up period. Medical costs included costs related to hospitalization, outpatient services, and emergency department visits. The costs include net charges billed by the healthcare provider to the payer and any fee that the payer was expecting the healthcare provider to collect from the patient.

\section{Statistical analysis}

The patients were stratified based on glycemic control ( $\mathrm{HbAlc}$ $<7 \%$ vs. HbAlc $\geq 7 \%$ ) using the mean HbAlc level measured during the 1-year follow-up period. The demographic and clinical characteristics included age, sex, nationality, health insurance plan, insulin use in the index diagnosis month, use of antidiabetic medications, and comorbidities diagnosed during the study period (i.e., the pre-index period during the 6 months prior to the index month and the 1-year follow-up period). Insulin use in the index month was an indicator variable to identify whether the patient was prescribed insulin in the index month. The use of antidiabetic medications was an indicator variable to identify whether the patient was prescribed any diabetic medication during the follow-up period. Finally, comorbidities during the study period included hypertension, hyperlipidemia, hypoglycemia, nephropathy, neuropathy, cardiovascular disease, cerebrovascular disease, obesity, rheumatoid arthritis (RA)/osteoarthritis (OA), and asthma/chronic obstructive pulmonary disease (COPD).

The demographic and clinical characteristics of the two patient groups ( $\mathrm{HbAlc}<7 \%$ vs. HbAlc $\geq 7 \%$ ) were compared using chisquare test. To adjust for these differences, the patients with glycemic control (HbAlc <7\%) were matched to those without glycemic control (HbAlc $\geq 7 \%$ ) using a propensity score. The propensity score, which is the conditional probability of assigning a patient to the group with glycemic control, was calculated to balance the patient characteristics of the two groups and therefore reduce the selection bias. ${ }^{23} \mathrm{~A}$ logistic regression was used to estimate the propensity score for each patient after adjusting the confounding variables such as nationality, health insurance plan, the use of insulin and oral antidiabetic medications in the index month, and comorbidities during the pre-index period.

Matching between the two groups was implemented by a 1:1 ratio using a greedy matching method, which pairs each case patient with a unique comparison patient based on the closest propensity scores without replacement. ${ }^{24}$ The patients in each group were stratified by age (four blocks) and sex (two blocks) in order to enhance the precision of the matching. Within each stratified block, patients with glycemic control were initiated to match on a 1:1 ratio with those without glycemic control on the basis of identical six-digit propensity scores, and continued until patients were matched with at least identical two-digit scores. If a patient with glycemic control had more than one match in the group without glycemic control, one of the patients without glycemic control was randomly selected. The mean c-statistic, which was calculated to ensure the ability of the propensity scores to effectively differentiate between the two groups, was 0.73 (range, 0.68-0.81).

To investigate the economic impact of glycemic control, diabetes-related costs were compared between the two groups. For the matched patients, the average annual diabetes-related cost per patient was calculated, and 95\% confidence intervals (CIs) were obtained using the bootstrap method because they did not follow the normal distribution. ${ }^{25} \mathrm{~A}$ paired $t$-test was used to detect statistically significant differences in diabetes-related costs between the two matched patients. Additionally, to examine the influence of age on diabetes-related costs between the two groups, the costs were compared by age groups (i.e., $\leq 44,45-54,55-64$, or $\geq 65$ years). 
The likelihood of controlling glycemic level was calculated using multivariable logistic regression after adjusting for age, sex, nationality, region, health insurance plan, insulin use in the index month, use of antidiabetic medications, and comorbidities during the study period. A generalized linear model (GLM) with a log link function and gamma distribution was used to determine significant factors associated with diabetes-related costs.

Diabetes-related costs attributable to glycemic control were defined as the difference in predicted diabetes-related costs between patients with glycemic control versus those without glycemic control, which were estimated using a recycled prediction method. First, the coefficients of the covariates (i.e., HbAlc control, age, sex, nationality, region, health insurance plan, insulin use in the index month, use of antidiabetic medications, and comorbidities during the study period) were calculated using GLM for diabetes-related costs in all matched patients. Once the coefficients were calculated, the diabetes-related costs for patients with glycemic control were predicted under the assumption that all matched patients had gly-

Table 1. Characteristics of diabetic patients before and after matching using propensity scores

\begin{tabular}{|c|c|c|c|c|c|c|c|}
\hline \multirow{2}{*}{ Variable } & \multirow{2}{*}{ Total } & \multicolumn{3}{|c|}{ Before matching } & \multicolumn{3}{|c|}{ After matching } \\
\hline & & $\mathrm{HbA1c}<7 \%$ & $\mathrm{HbA} 1 \mathrm{c} \geq 7 \%$ & $P$ & $\mathrm{HbA1c}<7 \%$ & $\mathrm{HbA1c} \geq 7 \%$ & $P$ \\
\hline Total & $6,693(100.0)$ & $3,117(100.0)$ & $3,576(100.0)$ & - & $2,029(100.0)$ & $2,029(100.0)$ & - \\
\hline Age (yr) & $48.9 \pm 11.5$ & $49.8 \pm 11.4$ & $48.1 \pm 11.6$ & $<0.001$ & $48.3 \pm 10.7$ & $47.9 \pm 11.0$ & 0.253 \\
\hline$\leq 44$ & 2,280 (34.1) & 991 (31.8) & $1,289(36.0)$ & $<0.001$ & $735(36.2)$ & 735 (36.2) & 1.000 \\
\hline $45-54$ & $2,465(36.8)$ & $1,169(37.5)$ & 1,296 (36.2) & & $768(37.9)$ & $768(37.9)$ & \\
\hline $55-64$ & 1,581 (23.6) & $748(24.0)$ & 833 (23.3) & & $446(22.0)$ & $446(22.0)$ & \\
\hline$\geq 65$ & $367(5.5)$ & $209(6.7)$ & $158(4.4)$ & & $80(3.9)$ & $80(3.9)$ & \\
\hline Sex & & & & $<0.001$ & & & 1.000 \\
\hline Male & $4,629(69.2)$ & $2,023(64.9)$ & $2,606(72.9)$ & & $1,445(71.2)$ & $1,445(71.2)$ & \\
\hline Female & 2,064 (30.8) & 1,094 (35.1) & $970(27.1)$ & & $584(28.8)$ & $584(28.8)$ & \\
\hline Nationality & & & & $<0.001$ & & & 0.968 \\
\hline National & $1,168(17.5)$ & $659(21.1)$ & $509(14.2)$ & & $303(14.9)$ & $298(14.7)$ & \\
\hline Expatriate & $4,723(70.6)$ & 2,076 (66.6) & $2,647(74.0)$ & & $1,458(71.9)$ & $1,465(72.2)$ & \\
\hline NA & $802(12.0)$ & $382(12.3)$ & $420(11.7)$ & & $268(13.2)$ & $266(13.1)$ & \\
\hline Health insurance plan & & & & $<0.001$ & & & 0.985 \\
\hline Basic & $3,040(45.4)$ & 1,194 (38.3) & $1,846(51.6)$ & & $941(46.4)$ & $944(46.5)$ & \\
\hline Enhanced & 2,395 (35.8) & $1,216(39.0)$ & $1,179(33.0)$ & & $772(38.0)$ & $773(38.1)$ & \\
\hline Thiqa & $1,258(18.8)$ & $707(22.7)$ & $551(15.4)$ & & $316(15.6)$ & $312(15.4)$ & \\
\hline Insulin at index month & & & & $<0.001$ & & & 1.000 \\
\hline None & $6,159(92.0)$ & $3,017(96.8)$ & $3,142(87.9)$ & & 1,942 (95.7) & $1,942(95.7)$ & \\
\hline Yes & $534(8.0)$ & $100(3.2)$ & $434(12.1)$ & & $87(4.3)$ & $87(4.3)$ & \\
\hline Use of antidiabetics* & & & & $<0.001$ & & & 1.000 \\
\hline None & 2,553 (38.1) & $1,601(51.4)$ & $952(26.6)$ & & $770(37.9)$ & $770(37.9)$ & \\
\hline Yes & $4,140(61.9)$ & $1,516(48.6)$ & $2,624(73.4)$ & & $1,259(62.1)$ & $1,259(62.1)$ & \\
\hline \multicolumn{8}{|c|}{ Comorbidity during pre-index period ${ }^{\dagger}$} \\
\hline Hypertension & $1,314(19.6)$ & $922(29.6)$ & $392(11.0)$ & 0.019 & $264(13.0)$ & $264(13.0)$ & 1.000 \\
\hline Hyperlipidemia & $1,419(21.2)$ & 1,051 (33.7) & $368(10.3)$ & 0.003 & $274(13.5)$ & $273(13.5)$ & 0.963 \\
\hline Nephropathy & $52(0.8)$ & $43(1.4)$ & $9(0.3)$ & $<0.001$ & $4(0.2)$ & $1(0.0)$ & 0.179 \\
\hline Neuropathy & $137(2.0)$ & $102(3.3)$ & $35(1.0)$ & $<0.001$ & $11(0.5)$ & $11(0.5)$ & 1.000 \\
\hline Cardiovascular disease & $201(3.0)$ & $148(4.7)$ & $53(1.5)$ & $<0.001$ & $25(1.2)$ & $25(1.2)$ & 1.000 \\
\hline Cerebrovascular disease & $57(0.9)$ & $41(1.3)$ & $16(0.4)$ & $<0.001$ & $3(0.1)$ & $4(0.2)$ & 0.705 \\
\hline Obesity & $194(2.9)$ & $144(4.6)$ & $50(1.4)$ & $<0.001$ & $20(1.0)$ & $21(1.0)$ & 0.875 \\
\hline $\mathrm{RA} / \mathrm{OA}$ & $294(4.4)$ & $221(7.1)$ & $73(2.0)$ & $<0.001$ & $37(1.8)$ & $39(1.9)$ & 0.817 \\
\hline Asthma/COPD & $274(4.1)$ & $179(5.7)$ & $95(2.7)$ & $<0.001$ & $39(1.9)$ & $38(1.9)$ & 0.908 \\
\hline
\end{tabular}

Values are presented as number (\%) or mean \pm standard deviation.

${ }^{*}$ Use of antidiabetic medications during 1-year follow-up period; ' ${ }^{C}$ Comorbidities detected during 6 months prior to index month (i.e., pre-index period). HbA1c, glycosylated hemoglobin; NA, not available; RA, rheumatoid arthritis; OA, osteoarthritis; COPD, chronic obstructive pulmonary disease. 
cemic control (i.e., dummy variable for $\mathrm{HbAlc}$ control was 0 ). Similarly, the costs for patients without glycemic control were predicted under the assumption that all matched patients did not have glycemic control (i.e., dummy variable for HbAlc control was 1). The differences between the two predicted costs were identified as the diabetes-related costs attributable to glycemic control in patients with diabetes. ${ }^{26-28}$

All costs were converted to 2015 UAE dirhams (AED) using the consumer price index and to US dollars using the exchange rate (USD 1 = AED 3.67). Data were analyzed using SAS ver. 9.2 (SAS Institute, Cary, NC, USA) and STATA ver. 10.1 (STATA Corp., College Station, TX, USA).

\section{RESULTS}

Table 1 presents characteristics of 6,693 identified patients. The mean age was 48.9 years, $69.2 \%$ of the patients were male, and the majority were expatriates (70.6\%). In terms of medical condition, $61.9 \%$ of the patients were taking antidiabetic medications and $40.8 \%$ were also diagnosed with hypertension (19.6\%) and/or hyperlipidemia (21.2\%). Demographic and clinical characteristics of patients were significantly different between patients who controlled $\mathrm{HbAlc}(\mathrm{HbAlc}<7 \%)$ and patients who did not control $\mathrm{HbAlc}(\mathrm{HbAlc} \geq 7 \%)$. The patients with controlled HbAlc during the follow-up period were older and more likely to be female, a
UAE national, a Thiqa insurance plan enrollee, and not use insulin during the index diagnosis month. Furthermore, $51.4 \%$ of the patients with controlled $\mathrm{HbAlc}$ did not take antidiabetic medications, compared with $26.6 \%$ of the patients with uncontrolled $\mathrm{HbAlc}$. However, after matching these two groups using the propensity scores, differences in all characteristics of two group patients could not be found.

Annual total treatment costs in patients with controlled glycemic level were $\$ 3,285$, while total costs were $\$ 3,315$ in patients with uncontrolled glycemic level (Table 2). Of these total costs, the diabetes-related costs were $\$ 2,282$ and $\$ 2,667$ per year for patients with $\mathrm{HbAlc}<7 \%$ and $\mathrm{HbAlc} \geq 7 \%$, respectively. In both groups, two-thirds of the diabetes-related costs were medical costs, of which outpatient visits were the biggest component. In the analysis of the diabetes-related costs stratified by patients' age after matching (Fig. 1), the difference in diabetes-related costs between patients with and without glycemic control was smallest in the 45-54 year age group $(\$ 2,088$ vs. $\$ 2,217)$, and the difference increased with age. In general, Table 3 presents that the diabetes-related costs attributable to poor glycemic control were estimated at \$172 (95\% CI, \$164-180), which were defined as the difference in the costs between patients with $\mathrm{HbAlc} \geq 7 \%$ and patients with $\mathrm{HbAlc}<7 \%$ after adjustment for differences in covariates between matched patient groups using the recycled prediction method.

Table 4 presents that factors influencing glycemic control and di-

Table 2. Annual total treatment costs and diabetes-related costs in matched patients with diabetes

\begin{tabular}{|c|c|c|c|c|c|}
\hline \multirow{2}{*}{ Variable } & \multicolumn{2}{|c|}{$\mathrm{HbA} 1 \mathrm{c}<7 \%(\mathrm{n}=2,029)$} & \multicolumn{2}{|c|}{$\mathrm{HbA} 1 \mathrm{c} \geq 7 \%(\mathrm{n}=2,029)$} & \multirow{2}{*}{$P$} \\
\hline & Mean & Bootstrap 95\% Cl & Mean & Bootstrap 95\% Cl & \\
\hline Total treatment cost (\$) & 3,285 & $3,082-3,488$ & 3,315 & $3,105-3,524$ & 0.808 \\
\hline Medical cost & 2,314 & $2,149-2,479$ & 2,278 & $2,100-2,457$ & 0.739 \\
\hline Inpatient & 333 & $258-407$ & 408 & $286-530$ & 0.311 \\
\hline Outpatient & 1,946 & $1,812-2,081$ & 1,826 & $1,718-1,933$ & 0.078 \\
\hline Emergency visit & 35 & $27-42$ & 45 & $34-56$ & 0.136 \\
\hline Prescription cost & 971 & $904-1,038$ & 1,036 & $972-1,100$ & 0.096 \\
\hline Diabetes-related cost (\$) & 2,282 & $2,142-2,421$ & 2,667 & $2,479-2,855$ & $<0.001$ \\
\hline Medical cost & 1,530 & $1,423-1,638$ & 1,778 & $1,616-1,940$ & 0.005 \\
\hline Inpatient & 262 & 191-332 & 369 & $244-494$ & 0.137 \\
\hline Outpatient & 1,255 & $1,181-1,329$ & 1,387 & $1,300-1,473$ & $<0.001$ \\
\hline Emergency visit & 14 & 10-18 & 22 & $13-31$ & 0.084 \\
\hline Prescription cost & 751 & 701-802 & 890 & 836-944 & $<0.001$ \\
\hline
\end{tabular}

All costs were converted to 2015 AED using the Consumer Price Index and to US dollars using the exchange rate ( $\$ 1=A E D 3.67$ ). $\mathrm{HbA1c}$, glycosylated hemoglobin; $\mathrm{Cl}$, confidence interval; AED, United Arab Emirates dirhams. 


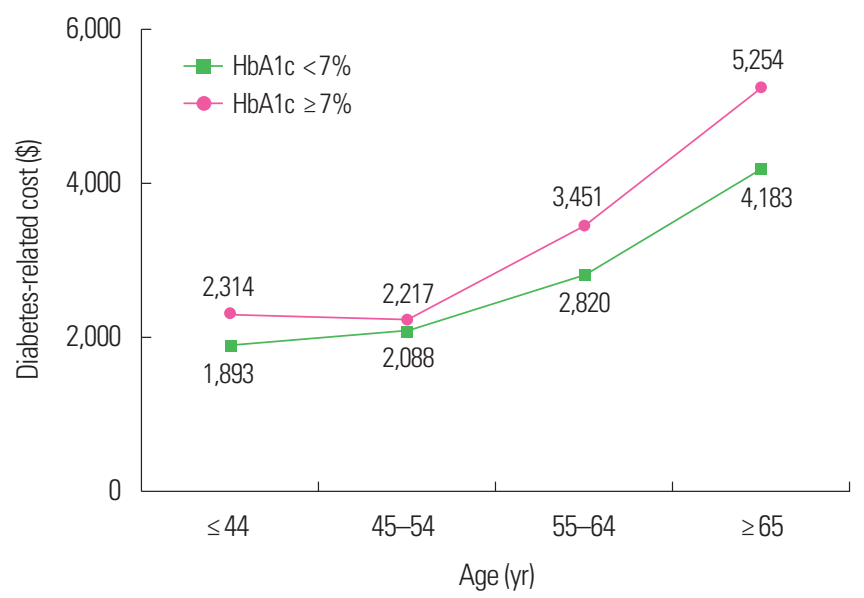

Figure 1. Diabetes-related costs by age in matched patients with diabetes. HbA1c, glycosylated hemoglobin.

Table 3. Diabetes-related treatment costs attributable to uncontrolled glycemic level

\begin{tabular}{lcc}
\hline Variable & Mean (\$) & Bootstrap 95\% Cl \\
\hline Costs attributable to uncontrolled $\mathrm{HbA} 1 \mathrm{c}^{*}$ & 172 & $164-180$ \\
Predicted cost of patients with $\mathrm{HbA} 1 \mathrm{c}<7 \%^{\dagger}$ & 2,529 & $2,411-2,648$ \\
Predicted cost of patients with $\mathrm{HbA} 1 \mathrm{c} \geq 7 \%^{\dagger}$ & 2,701 & $2,575-2,827$ \\
\hline
\end{tabular}

* Costs attributable to the uncontrolled $\mathrm{HbA1c}$ were the differences in the predicted costs between patients with controlled glycemic level $(<7 \%)$ and patients with uncontrolled glycemic level; 'Predicted costs were calculated using a generalized linear model with a log link function and gamma distribution.

$\mathrm{Cl}$, confidence interval; HbA1c, glycosylated hemoglobin.

abetes related treatment costs after adjusting for the study variables respectively. After controlling for study variables, patients who were old age (age $\geq 65$ years) are more likely to control their glucose level than those patient aged under 44 years (OR, 1.30; 95\% CI, 1.01-1.67). In addition patients were more likely to control their glucose level during the follow-up period if they are female (OR, $1.21 ; 95 \%$ CI, 1.07-1.37). Patients enrolled in the Thiqa or Enhanced plan were 1.48 and 1.65 times more likely to have glycemic control than those patients who had basic insurance plan respectively. However, insulin users in the index diagnosis month (OR, $0.34 ; 95 \% \mathrm{CI}, 0.27-0.43$ ) and users of antidiabetic medications during the follow-up period (OR, 0.43; 95\% CI, 0.38-0.47) were less likely to have glycemic control. In addition, the odds of glycemic control decreased significantly with hypoglycemia, retinopathy/macula edema, and neuropathy, but increased with RA/OA and asthma/COPD.

Table 4 also present cost ratios associated with diabetes treat-
Table 4. Factors associated with control of glycemic level and diabetes-related treatment costs

\begin{tabular}{|c|c|c|c|c|}
\hline \multirow[t]{2}{*}{ Variable } & \multicolumn{2}{|c|}{ Control of $\mathrm{HbA} 1 \mathrm{c}^{*}$} & \multicolumn{2}{|c|}{$\begin{array}{l}\text { Diabetes-related } \\
\text { treatment cost }^{\dagger}\end{array}$} \\
\hline & $\mathrm{OR}(95 \% \mathrm{Cl})$ & $P$ & Cost ratio (95\% Cl) & $P$ \\
\hline \multicolumn{5}{|l|}{ Control of $\mathrm{HbA1c}$} \\
\hline $\begin{array}{l}\mathrm{HbA} 1 \mathrm{c} \geq 7 \% \\
\quad \text { (uncontrolled) }\end{array}$ & - & & 1 & \\
\hline $\begin{array}{l}\mathrm{HbA} 1 \mathrm{c}<7 \% \\
\text { (controlled) }\end{array}$ & - & & $0.94(0.88-0.99)$ & 0.022 \\
\hline \multicolumn{5}{|l|}{ Age (yr) } \\
\hline$\leq 44$ & 1 & & 1 & \\
\hline $45-54$ & $1.07(0.95-1.22)$ & 0.268 & $1.01(0.94-1.08)$ & 0.786 \\
\hline $55-64$ & $1.03(0.89-1.19)$ & 0.702 & $1.09(1.01-1.18)$ & 0.031 \\
\hline$\geq 65$ & $1.30(1.01-1.67)$ & 0.042 & $1.45(1.25-1.70)$ & $<0.001$ \\
\hline \multicolumn{5}{|l|}{ Sex } \\
\hline Male & 1 & & 1 & \\
\hline Female & $1.21(1.07-1.37)$ & 0.003 & $1.05(0.98-1.13)$ & 0.139 \\
\hline \multicolumn{5}{|l|}{ Health insurance plan } \\
\hline Basic & 1 & & 1 & \\
\hline Enhanced & $1.65(1.45-1.88)$ & $<0.001$ & $2.63(2.45-2.82)$ & $<0.001$ \\
\hline Thiqa & $1.48(1.03-2.12)$ & 0.036 & $4.58(3.59-5.83)$ & $<0.001$ \\
\hline \multicolumn{5}{|c|}{ Insulin at index month } \\
\hline No & 1 & & 1 & \\
\hline Yes & $0.34(0.27-0.43)$ & $<0.001$ & $1.61(1.40-1.86)$ & $<0.001$ \\
\hline \multicolumn{5}{|c|}{ Use of antidiabetic medications } \\
\hline No & 1 & & 1 & \\
\hline Yes & $0.43(0.38-0.47)$ & $<0.001$ & $1.65(1.55-1.75)$ & $<0.001$ \\
\hline \multicolumn{5}{|c|}{ Comorbidity during study period } \\
\hline Hypertension & $0.99(0.88-1.11)$ & 0.802 & $1.20(1.13-1.28)$ & $<0.001$ \\
\hline Hyperlipidemia & $1.21(0.96-1.51)$ & 0.101 & $1.11(0.99-1.25)$ & 0.086 \\
\hline Hypoglycemia & $0.71(0.55-0.93)$ & 0.013 & $1.44(1.24-1.66)$ & $<0.001$ \\
\hline $\begin{array}{l}\text { Retinopathy/ } \\
\text { macular edema }\end{array}$ & $0.60(0.49-0.74)$ & $<0.001$ & $1.63(1.47-1.82)$ & $<0.001$ \\
\hline Nephropathy & 1.09 (0.88-1.35) & 0.416 & $1.37(1.22-1.55)$ & $<0.001$ \\
\hline Neuropathy & $0.73(0.65-0.81)$ & $<0.001$ & $1.28(1.20-1.36)$ & $<0.001$ \\
\hline $\begin{array}{l}\text { Cardiovascular } \\
\text { disease }\end{array}$ & $1.01(0.86-1.18)$ & 0.942 & $2.04(1.85-2.25)$ & $<0.001$ \\
\hline $\begin{array}{l}\text { Cerebrovascular } \\
\text { disease }\end{array}$ & 0.98 (0.79-1.23) & 0.875 & $1.90(1.66-2.18)$ & $<0.001$ \\
\hline Obesity & 1.16 (0.98-1.36) & 0.080 & $1.30(1.19-1.43)$ & $<0.001$ \\
\hline $\mathrm{RA} / \mathrm{OA}$ & $1.66(1.42-1.96)$ & $<0.001$ & $1.05(0.96-1.16)$ & 0.310 \\
\hline Asthma/COPD & $1.19(1.01-1.41)$ & 0.039 & $1.06(0.96-1.17)$ & 0.270 \\
\hline
\end{tabular}

${ }^{*} \mathrm{ORs}$ of controlling of $\mathrm{HbA1c}$ level were estimated using logistic regression after adjusting for the study variables; 'Diabetes-related costs were estimated using a generalized linear model with a log link function and gamma distribution.

HbA1c, glycosylated hemoglobin; OR, odds ratio; $\mathrm{Cl}$, confidence interval; RA, rheumatoid arthritis; $\mathrm{OA}$, osteoarthritis; $\mathrm{COPD}$, chronic obstructive pulmonary disease.

ment after adjusting for the study variables. Diabetes-related treatment costs in patients with controlled glycemic level ( $\mathrm{HbAlc}$ $<7 \%)$ were $6 \%$ lower than those of patients with uncontrolled gly- 
cemic level (HbAlc $\geq 7 \%$; cost ratio, 0.94; 95\% CI, 0.88-0.99). Compared with those aged $\leq 44$ years, diabetes-related costs were significantly higher in patients aged $\geq 65$ years (cost ratio, 1.45 ; 95\% CI, 1.25-1.70) and in patients aged 55-64 years (cost ratio, 1.09; 95\% CI, 1.01-1.18). Patients with the Enhanced or Thiqa insurance plan had significantly higher diabetes-related treatment costs (cost ratio, 2.63 and 4.58, respectively). The treatment costs for patients who used insulin in the index diagnosis month were 1.61 times higher than for those who did not. In addition, the treatment cost in patients with the use of antidiabetic medications was 1.65 times higher than those without these medications. Patients with hypertension, hypoglycemia, retinopathy/macular edema, nephropathy, neuropathy, cardiovascular disease, cerebrovascular disease, and obesity had significantly higher diabetes-related costs than those without.

\section{DISCUSSION}

In our analysis, $46.6 \%$ of patients with diabetes residing in $\mathrm{Abu}$ Dhabi, UAE achieved the HbAlc goal of $<7 \%$ during the 1-year follow-up period, which is higher than previous observations in other populations: $33.3 \%$ in the $\mathrm{Al}$ Ain Emirate of the $\mathrm{UAE}^{13}$, $34.9 \%$ in Jordan ${ }^{29}, 31 \%$ in the United Kingdom (HbAlc $\left.\leq 7.5 \%\right)^{9}$, and $29 \%$ of patients with diabetes receiving medical treatment in a managed care setting in the United States. ${ }^{30}$ In the present study, the higher rate of glycemic control in Abu Dhabi is primarily explained by the selection of patients with diabetes in the first year of their disease.

Several patient characteristics influenced glycemic control. Similar to previous studies that showed that younger age was associated with worse glycemic control in diabetes ${ }^{7,8,19,31}$, patients aged $\geq 65$ years were $30 \%$ more likely to have good glycemic control than patients $<44$ years old. This might be due in part to higher HbAlc levels in early onset diabetes patients compared with late onset patients. ${ }^{32}$ Second, older adult patients with T2DM might have improved adherence to oral antidiabetic medications. ${ }^{33} \mathrm{~A} 10 \%$ increase in adherence to oral antidiabetic medications was associated with a $0.1 \%$ decrease in $\mathrm{HbAlc}$, when controlled for baseline $\mathrm{HbAlc}$ and therapy regimen. ${ }^{33}$ In our analysis, female patients with diabetes had better glycemic control, which was consistent with a study conducted in the United States ${ }^{8}$ but not with studies conducted in Finland and Saudi Arabia. ${ }^{34,35}$ Thus, sex-related cultural differences might also affect glycemic control.

Socioeconomic situation might also influence the patients' ability to regulate glycemic levels. The Enhanced and Thiqa insurance plans, which represent the best health insurance coverage in UAE, were significantly associated with better glycemic control than the Basic plan. Similarly, the prevalence of poor glycemic control was highest among the uninsured in the United States ${ }^{19}$, including higher $\mathrm{HbAlc}$ levels in the uninsured in a low-income, multiethnic population with T2DM in the San Diego County. ${ }^{7}$ Also, the type of insurance coverage was a risk factor for sustained poor glycemic control in patients with type 1 diabetes in Hawaii. ${ }^{31}$

Clinical characteristics that affected glycemic control included the use of insulin and oral antidiabetic medications. Insulin use in the index diagnosis month and use of antidiabetic medications during the follow-up period were inversely associated with glycemic control, independent of the covariates. Patients with T2DM who require insulin, alone or in combination with oral antidiabetic medications, consistently have higher $\mathrm{HbAlc}$ values than those taking no medication or oral medications only. ${ }^{7,929}$ Compared with the use of only oral antidiabetic agents, the odds of poor glycemic control were four times higher with insulin alone and 7.5 times higher with combined oral antidiabetic agents and insulin. ${ }^{29}$ Furthermore, sustained poor glycemic control was observed in patients with diabetes taking more medication of any kind. ${ }^{31}$ Insulin use could represent disease severity to some extent. Diabetes duration could also be used to indicate disease severity, and there is considerable evidence indicating that longer diabetes durations are related with poor glycemic control. ${ }^{7,29,31,36}$ However, owing to the short follow-up period, the relationships between the onset of diabetes, diabetes duration, and glycemic control could not be examined in our analysis. Comorbidities that are diabetes-related complications, such as retinopathy/macular edema and neuropathy, could also reflect disease severity and negatively affect glycemic control, while comorbidities that are not related with diabetes could reflect increased adherence to antidiabetic medications ${ }^{33}$, thereby improving glycemic control. In the present study, comorbidities were significantly associated with glycemic control; the differing relationship directions might reflect the different influences of diabetes-related 
and non-diabetes-related comorbidities.

A mean $\mathrm{HbAlc}<7 \%$ during the follow-up period was associated with $25 \%$ lower diabetes-related costs, which supports previous research reporting significant relationships between uncontrolled $\mathrm{HbAlc}$ and increased health care costs in patients with T2DM. ${ }^{20,21,37}$ In a large managed care setting in the United States, the estimated total diabetes-related cost during the 1-year follow-up period was $\$ 1,594$ per patient with T2DM and $\mathrm{HbAlc}>7 \%$, which was $32 \%$ higher than the costs for those achieving the glycemic target. ${ }^{37}$ In our analysis, a patient with $\mathrm{HbA1c}<7 \%$ incurred 32\% less prescription drug costs and $22 \%$ less medical costs related to diabetes than a patient with $\mathrm{HbA1c} \geq 7 \%$. Similarly, a patient with T2DM and $\mathrm{HbAlc} \leq 7 \%$ incurred $20 \%$ less direct medical costs attributable to diabetes and $11 \%$ less antidiabetic prescription drugs costs annually than a patient with $\mathrm{HbAlc}>9 \%$ in a US-based study. ${ }^{21}$ The impact of glycemic control on costs may be a result of medication adherence. Previous research showed that good adherence to insulin in patients with insulin-dependent diabetes was associated with reduced hospital admissions for diabetic ketoacidosis and all hospital admissions related to acute diabetes complications in patients with insulin-dependent diabetes. ${ }^{38}$

Diabetes-related costs were higher in elderly patients $(\geq 65$ years) and those of UAE nationality as well as with better health insurance coverage and the use of insulin and antidiabetic medications in the index diagnosis month. The positive association between patient's age and diabetes-related costs was previously observed in the UAE and other countries. ${ }^{15,20}$ The association between insurance coverage and costs in patients with diabetes was also noted in the United States ${ }^{21}$; compared with only Medicare insurance, additional commercial health insurance was associated with higher diabetes-related medical and prescription drug costs. In the UAE, the direct medical costs of diabetes and its complications increase with diabetes duration and the use of insulin. ${ }^{15}$ Moreover, Brandle et al. ${ }^{39}$ estimated that a patient with T2DM treated with oral antidiabetic medications or insulin had 1.10 or 1.59 times, respectively, the direct medical costs of a patient with diet-controlled diabetes. In addition, most comorbidities in the present study increased diabetes-related costs, which was consistent with previous research ${ }^{20,39}$ that reported increased health care costs with the presence of hypertension, dyslipidemia, cardiovascular disease ${ }^{20}$, dia- betic kidney disease, cerebrovascular disease, or peripheral vascular disease.

To our knowledge, this study is the first to examine factors associated with glycemic control and diabetes-related costs in the UAE using administrative healthcare claims data. There are several strengths of this analysis, including data from patient claims records, large sample size, and representativeness of the UAE patient population with different access to health care. Nonetheless, the findings of this study should be interpreted with caution owing to certain limitations. First, this study could not examine several factors known to be associated with glycemic control and diabetes-related costs, such as compliance to medications ${ }^{29}$, obesity indices including body mass index and waist circumference ${ }^{36}$, patient's attitudes toward ${ }^{29}$, self-care behaviors such as glucose monitoring ${ }^{29}$ and lifestyle (diet, exercise, smoking, drinking) ${ }^{29,36}$ because the information was not available in the data set. Second, we could consider the time from the initial diagnosis of diabetes, which can influence the response to antidiabetic medication, level of glycemic control, onset of complications, and diabetes-related costs. Instead, we attempted to include only new patients with diabetes; however, the length of the pre-index period ( 6 months) may be too short to exclude patients with a previous diagnosis of diabetes. Third, this study may be subject to misclassification bias in the claims database. Also, the cost analysis was based on diagnostic codes of diabetes and the use of antidiabetic drugs. This may have resulted in underestimation of total costs associated with diabetes. Further studies using large datasets and longer follow-up periods are needed to determine causality and control for important confounders such as diabetes severity.

In the capital of the UAE (Abu Dhabi), $46.6 \%$ of patients with mild diabetes were able to maintain their $\mathrm{HbAlc}$ level below the recommended $7 \%$ over the first year of the disease. Diabetes-related costs were higher in patients with poorly controlled diabetes, which significantly increased with age. Glycemic control was associated with lower costs in patients enrolled in the Enhanced or Thiqa insurance plan. However, diabetes-related costs were higher for the patients enrolled in these plans, compared with the Basic plan, suggesting that financial situation might limit the ability to delay disease progression. Thus, it may be advantageous to improve the coverage of the Basic plan at an affordable cost for low-income 
patients to reduce the future expenses associated with the treatment of severe disease complications.

\section{CONFLICTS OF INTEREST}

This study was partially supported by research grants of Novartis Pharmaceuticals Co. The funder did not play any role in the study design, data collection and analysis, decisions regarding data release, or manuscript preparation. The authors declare no other conflict of interest.

\section{ACKNOWLEDGMENTS}

The authors would like to express their gratitude to Mr. Andrey Timoshkin and Mr. Mohammed Fakhreddine for their contribution and helpful comments on the study.

This study was partially supported by research grants of Novartis Pharmaceuticals Co.

\section{REFERENCES}

1. Guariguata L, Whiting DR, Hambleton I, Beagley J, Linnenkamp U, Shaw JE. Global estimates of diabetes prevalence for 2013 and projections for 2035. Diabetes Res Clin Pract 2014; 103:137-49.

2. Malik M, Bakir A, Saab BA, King H. Glucose intolerance and associated factors in the multi-ethnic population of the United Arab Emirates: results of a national survey. Diabetes Res Clin Pract 2005;69:188-95.

3. UAE National Diabetes Committee. National diabetes guidelines United Arab Emirates 2009. The United Arab Emirates: UAE National Diabetes Committee; 2009.

4. Alberti KG, Zimmet P, Shaw J; IDF Epidemiology Task Force Consensus Group. The metabolic syndrome: a new worldwide definition. Lancet 2005;366:1059-62.

5. Gaster B, Hirsch IB. The effects of improved glycemic control on complications in type 2 diabetes. Arch Intern Med 1998; 158:134-40.

6. Davila EP, Florez H, Trepka MJ, Fleming LE, Niyonsenga T, Lee DJ, et al. Strict glycemic control and mortality risk among
US adults with type 2 diabetes. J Diabetes Complications 2011; 25:289-91.

7. Benoit SR, Fleming R, Philis-Tsimikas A, Ji M. Predictors of glycemic control among patients with type 2 diabetes: a longitudinal study. BMC Public Health 2005;5:36.

8. Nichols GA, Hillier TA, Javor K, Brown JB. Predictors of glycemic control in insulin-using adults with type 2 diabetes. Diabetes Care 2000;23:273-7.

9. Fox KM, Gerber Pharmd RA, Bolinder B, Chen J, Kumar S. Prevalence of inadequate glycemic control among patients with type 2 diabetes in the United Kingdom general practice research database: a series of retrospective analyses of data from 1998 through 2002. Clin Ther 2006;28:388-95.

10. Stratton IM, Adler AI, Neil HA, Matthews DR, Manley SE, Cull CA, et al. Association of glycaemia with macrovascular and microvascular complications of type 2 diabetes (UKPDS 35): prospective observational study. BMJ 2000;321:405-12.

11. American Diabetes Association. Standards of medical care in diabetes-2017. Diabetes Care 2017;40(Suppl 1):S1-135.

12. Stark Casagrande S, Fradkin JE, Saydah SH, Rust KF, Cowie CC. The prevalence of meeting AlC, blood pressure, and LDL goals among people with diabetes, 1988-2010. Diabetes Care 2013;36:2271-9.

13. Saadi H, Carruthers SG, Nagelkerke N, Al-Maskari F, Afandi B, Reed R, et al. Prevalence of diabetes mellitus and its complications in a population-based sample in Al Ain, United Arab Emirates. Diabetes Res Clin Pract 2007;78:369-77.

14. American Diabetes Association. Economic costs of diabetes in the U.S. in 2012. Diabetes Care 2013;36:1033-46.

15. Al-Maskari F, El-Sadig M, Nagelkerke N. Assessment of the direct medical costs of diabetes mellitus and its complications in the United Arab Emirates. BMC Public Health 2010;10:679.

16. Gilmer TP, O'Connor PJ, Manning WG, Rush WA. The cost to health plans of poor glycemic control. Diabetes Care 1997; 20:1847-53.

17. Stephens JM, Botteman MF, Hay JW. Economic impact of antidiabetic medications and glycemic control on managed care organizations: a review of the literature. J Manag Care Pharm 2006; 12:130-42.

18. Wagner EH, Sandhu N, Newton KM, McCulloch DK, Ramsey 
SD, Grothaus LC. Effect of improved glycemic control on health care costs and utilization. JAMA 2001;285:182-9.

19. Ali MK, McKeever Bullard K, Imperatore G, Barker L, Gregg EW; Centers for Disease Control and Prevention (CDC). Characteristics associated with poor glycemic control among adults with self-reported diagnosed diabetes: National Health and Nutrition Examination Survey, United States, 2007-2010. MMWR Suppl 2012;61:32-7.

20. Degli Esposti L, Saragoni S, Buda S, Sturani A, Degli Esposti E. Glycemic control and diabetes-related health care costs in type 2 diabetes: retrospective analysis based on clinical and administrative databases. Clinicoecon Outcomes Res 2013;5:193-201.

21. Oglesby AK, Secnik K, Barron J, Al-Zakwani I, Lage MJ. The association between diabetes related medical costs and glycemic control: a retrospective analysis. Cost Eff Resour Alloc 2006;4:1.

22. Sirgi C. Abu Dhabi healthcare system: a rational thinking based on data analysis. Hum Health 2012;21:10-4.

23. Rosenbaum PR, Rubin DB. The central role of the propensity score in observational studies for causal effects. Biometrika 1983;70:41-55.

24. Gu XS, Rosenbaum PR. Comparison of multivariate matching methods: structures, distances, and algorithms. J Comput Graph Stat 1993;2:405-20.

25. Desgagné A, Castilloux AM, Angers JF, LeLorier J. The use of the bootstrap statistical method for the pharmacoeconomic cost analysis of skewed data. Pharmacoeconomics 1998;13(5 Pt 1):487-97.

26. Manning WG, Mullahy J. Estimating log models: to transform or not to transform? J Health Econ 2001;20:461-94.

27. Basu A, Rathouz PJ. Estimating marginal and incremental effects on health outcomes using flexible link and variance function models. Biostatistics 2005;6:93-109.

28. Basu A, Arondekar BV, Rathouz PJ. Scale of interest versus scale of estimation: comparing alternative estimators for the incremental costs of a comorbidity. Health Econ 2006;15: 1091-107.

29. Khattab M, Khader YS, Al-Khawaldeh A, Ajlouni K. Factors associated with poor glycemic control among patients with type 2 diabetes. J Diabetes Complications 2010;24:84-9.

30. Beaton SJ, Nag SS, Gunter MJ, Gleeson JM, Sajjan SS, Alexander CM. Adequacy of glycemic, lipid, and blood pressure management for patients with diabetes in a managed care setting. Diabetes Care 2004;27:694-8.

31. Juarez DT, Sentell T, Tokumaru S, Goo R, Davis JW, Mau MM. Factors associated with poor glycemic control or wide glycemic variability among diabetes patients in Hawaii, 2006-2009. Prev Chronic Dis 2012;9:120065.

32. Chuang LM, Soegondo S, Soewondo P, Young-Seol K, Mohamed M, Dalisay E, et al. Comparisons of the outcomes on control, type of management and complications status in early onset and late onset type 2 diabetes in Asia. Diabetes Res Clin Pract 2006;71:146-55.

33. Rozenfeld Y, Hunt JS, Plauschinat C, Wong KS. Oral antidiabetic medication adherence and glycemic control in managed care. Am J Manag Care 2008;14:71-5.

34. Valle T, Koivisto VA, Reunanen A, Kangas T, Rissanen A. Glycemic control in patients with diabetes in Finland. Diabetes Care 1999;22:575-9.

35. Akbar DH. Low rates of diabetic patients reaching good control targets. East Mediterr Health J 2001;7:671-8.

36. Otiniano ME, Al Snih S, Goodwin JS, Ray L, AlGhatrif M, Markides KS. Factors associated with poor glycemic control in older Mexican American diabetics aged 75 years and older. J Diabetes Complications 2012;26:181-6.

37. Shetty S, Secnik K, Oglesby AK. Relationship of glycemic control to total diabetes-related costs for managed care health plan members with type 2 diabetes. J Manag Care Pharm 2005; 11:559-64.

38. Morris AD, Boyle DI, McMahon AD, Greene SA, MacDonald TM, Newton RW. Adherence to insulin treatment, glycaemic control, and ketoacidosis in insulin-dependent diabetes mellitus. The DARTS/MEMO collaboration: diabetes audit and research in Tayside Scotland. Medicines Monitoring Unit. Lancet 1997;350:1505-10.

39. Brandle M, Zhou H, Smith BR, Marriott D, Burke R, Tabaei BP, et al. The direct medical cost of type 2 diabetes. Diabetes Care 2003;26:2300-4. 